\title{
Nitrodi thermal water downregulates protein S-nitrosylation in RKO cells
}

\author{
ANTONIETTA AVERSANO $^{1 *}$, FRANCESCA WANDA ROSSI ${ }^{2 *}$, FRANCESCA CAMMAROTA ${ }^{1,3}$, \\ AMATO DE PAULIS ${ }^{2}$, PAOLA IZZO ${ }^{1,3^{*}}$ and MARINA DE ROSA ${ }^{1,3 *}$ \\ Departments of ${ }^{1}$ Molecular Medicine and Medical Biotechnology, and ${ }^{2}$ Translational Medical Sciences, \\ University of Naples Federico II, I-80131 Naples; ${ }^{3}$ CEINGE-Biotecnologie Avanzate, I-80145 Naples, Italy
}

Received January 30, 2020; Accepted June 23, 2020

DOI: $10.3892 / \mathrm{ijmm} .2020 .4676$

\begin{abstract}
Balneotherapy and spa therapy have been used in the treatment of ailments since time immemorial. Moreover, there is evidence to suggest that the beneficial effects of thermal water continue for months following the completion of treatment. The mechanisms through which thermal water exerts its healing effects remain unknown. Both balneological and hydroponic therapy at 'the oldest spa in the world', namely, the Nitrodi spring on the Island of Ischia (Southern Italy) are effective in a number of diseases and conditions. The aim of the present study was to investigate the molecular basis underlying the therapeutic effects of Nitrodi spring water in low-grade inflammation and stress-related conditions. For this purpose, an in vitro model was devised in which RKO colorectal adenocarcinoma cells were treated with phosphate-buffered saline or phosphate-buffered saline prepared with Nitrodi water for $4 \mathrm{~h}$ daily, 5 days a week for 6 weeks. The RKO cells were then subjected to the following assays: $3-(4,5-$ Dimethylthiazol-2-yl)-2,5-diphenyl-2H-tetrazolium bromide assay, Transwell migration assay, western blot analysis, the fluorimetric detection of protein S-nitrosothiols and S-nitrosylation western blot analysis. The results revealed that Nitrodi spring water promoted cell migration and cell viability, and downregulated protein S-nitrosylation, probably also the nitrosylated active form of the cyclooxygenase (COX)-2 protein. These results concur with all the previously reported
\end{abstract}

Correspondence to: Professor Marina De Rosa, Department of Molecular Medicine and Medical Biotechnology, University of Naples Federico II, Via S. Pansini 5, I-80131 Naples, Italy

E-mail: derosam1966@gmail.com

Professor Francesca Wanda Rossi, Department of Translational Medical Sciences, University of Naples Federico II, Via S. Pansini 5, I-80131 Naples, Italy

E-mail: frawrossi@yahoo.it

*Contributed equally

Key words: balneotherapy, thermal mineral water, protein nitrosylation, cyclooxygenase-2 inactivation, anti-inflammatory effect therapeutic properties of Nitrodi spring water, and thus reinforce the concept that this natural resource is an important complementary therapy to traditional medicine.

\section{Introduction}

Balneotherapy is a clinically effective complementary approach to the treatment of low-grade inflammation and stress-related conditions (1). The biological mechanisms through which immersion in mineral-medicinal water and the application of mineral mud alleviate symptoms of various diseases remain largely unknown. However, it is known that neuroendocrine and immunological responses to balneotherapy, including humoral and cell-mediated immunity, are involved in these mechanisms, and lead to anti-inflammatory, analgesic, antioxidant, chondroprotective and anabolic effects, as well as to neuroendocrine-immune regulation in various conditions $(2,3)$.

The Campania region of Southern Italy is one of the richest regions worldwide in terms of thermal and mineral water resources. Indeed, thanks to their chemical and physical properties, these waters have been used for therapeutic purposes since Roman times (4-6). The Nitrodi spring on the Island of Ischia in the Bay of Naples was known to the Romans 2,000 years ago, as witnessed by marble votive reliefs dated between the first century B.C. and the second century A.D. found on the island. Notably, a School of Medical Hydrology attended by such prominent physicians as Menippo, Aurelius Monnus, Numerius Fabius, was linked to the Nitrodi springs. It has been suggested that its name is derived from the word 'nitro', namely 'soda' as the waters were believed to be rich in this compound.

Thermal mineral water is classified based on its chemical composition and temperature in low mineralized, mildly mineralized and highly mineralized, and cold $\left(<20^{\circ} \mathrm{C}\right)$, hypothermal $\left(20-30^{\circ} \mathrm{C}\right)$, thermal $\left(>30-40^{\circ} \mathrm{C}\right)$ and hyperthermal $\left(>40^{\circ} \mathrm{C}\right)(7)$. The Marotta and Sica classification $(8,9)$, which is the most widely accredited classification in Italy (10), is based on temperature, fixed residue and chemical composition $(8,9)$. According to this classification, Nitrodi water is classified as follows: 'Medium mineral content, thermal waters, bicarbonate, sulphate and alkaline, and earthy' $(8,9)$. Its dry residue at $180^{\circ} \mathrm{C}$ is approximately $0.9598 \mathrm{~g} / 1$, its source temperature is approximately $28^{\circ} \mathrm{C}$, 
its concentration is approximately $0.4758 \mathrm{~g} / 1 \mathrm{HCO}_{3}^{-}, 0.2200 \mathrm{~g} / \mathrm{l}$ $\mathrm{SO}_{4}^{-}, 0.1676 \mathrm{~g} / \mathrm{l} \mathrm{NA}{ }^{+}$and $0.1182 \mathrm{~g} / 1 \mathrm{Ca}^{++}$(dry residue component of 11 water: $\mathrm{Na}, 0.167 \mathrm{~g}$; $\mathrm{Ca}^{++} 0.118 \mathrm{~g} ; \mathrm{SO}_{4}^{-}, 0.220 \mathrm{~g} ; \mathrm{CO}_{3}^{-}$, $0.234 \mathrm{~g}$ ). Its main components are sodium, calcium, chlorine, sulphur and carbon (11). Although the last official analysis of Nitrodi water dates back to 1984 , the findings were confirmed by the University of Naples Federico II in an analysis conducted in 2003, which was recognized by the Italian Ministry of Health (Decree no. 3509, October 9, 2003 'https://www.fonteninfenitrodi.com/la-fonte/pubblicazioni'), and by a chemical and chemical-physical analysis in 2018 , which issued a signed report (unpublished data).

Moreover, in October, 2003, the Italian Ministry of Health recognised the therapeutic properties of Nitrodi water. Indeed, when ingested or when applied in the form of mud baths, it has been proven to be effective in the treatment of various ailments $(6,11)$. For example, in the 1950s, Mancioli (11) reported that Nitrodi water promoted and regulated diuresis, improved the functional capacity of the kidneys, and resolved or greatly alleviated gastritis and gastroduodenitis. It is also an excellent adjuvant in the treatment of gastroduodenal ulcers, varicose veins, wounds, fistulas and pimples, and improves the health and appearance of the skin (11). However, the molecular mechanisms underlying the beneficial effects of Nitrodi water have not yet been elucidated. Thus, the present study evaluated the molecular basis of the benefits of Nitrodi water on wound healing and in inflammatory diseases.

\section{Materials and methods}

Cell lines and culture. The RKO cell line (ATCC) was used to explore the molecular basis of the beneficial effects of Nitrodi waters on 'inflammatory diseases' as they overexpress IL-6 and IL-6 receptors (12), which are the main cytokines of the inflammatory cascade (13) and several inflammatory diseases involving the gastrointestinal compartment. The RKO cells were grown in Eagle's minimum essential medium supplemented with $10 \%$ fetal bovine serum, $100 \mathrm{U} / \mathrm{ml}$ penicillin and $100 \mu \mathrm{g} / \mathrm{ml}$ streptomycin (completed medium). The cells were treated with phosphate-buffered saline (PBS) prepared with Nitrodi water (PBS-Nitrodi) for 4 h/day, 5 days a week, for 6 weeks and analysed as described below. Treatment with PBS alone served as the control.

Migration assays. Cell migration was evaluated using in vitro Boyden chamber and wound healing assays as described elsewhere (14). Briefly, to perform wound healing assays, the cells treated as described above for 6 weeks were seeded at $1 \times 10^{4}$ cells/well in 6-well plates. After the cells formed a monolayer (95-100\% confluence) cells was rinsed and then medium without FBS was added overnight (14 h); subsequently, scratch wounds were made with the tip of a $200-\mu 1$ pipette, and the scratch was photographed under a light microscope (Leica Automated Inverted Microscope for Life Science Research Leica DMI4000 B, Type DMI400B 11888318, serial number $279034)$ at $x 5$ magnification. The cells were again incubated for $4 \mathrm{~h}$ with PBS (RKO-PBS) or PBS-Nitrodi (RKO-Nitrodi), rinsed and then medium without FBS was added. Finally, after $24 \mathrm{~h}$ from the scratch, cells were photographed a second time. The experiment was repeated 3 times.
A Boyden chamber assay was performed using the $\mathrm{QCM}^{\mathrm{TM}}$ 24-well colorimetric cell migration assay systems (pore size: $8.0 \mu \mathrm{m}$; EMD Millipore). A $300 \mu \mathrm{l}$ aliquot of a $1 \times 10^{6} \mathrm{cells} / \mathrm{ml}$ suspension was resuspended in serum-free medium and seeded in the upper chamber of a 24-well insert. Subsequently, $500 \mu \mathrm{l}$ of free medium (prepared according to the manufacturer's instructions) was added to the lower well of the migration plate. Finally, the cells were removed from the top of the membrane, the migrated cells were stained for $10 \mathrm{~min}$ at room temperature with crystal violet solution (Sigma-Aldrich; Merck KGaA), the stain was extracted and optical density was measured at wavelength of $560 \mathrm{~nm}$ according to the manufacturer's instructions (BioTek Synergy Microplate Reader; BioTek Instruments, Inc.). The results represent the median of 4 experiments.

Cell viability assay. Cell viability was analysed by 3-(4,5-dimethylthiazol-2-yl)-5-(3-carboxymethxyphenyl)-2-(4-sulfophenyl)-2H tetrazolium (MTT) assay as previously described (15). Cell suspensions (500 $\mu$ l) from the RKO-PBS and RKO-Nitrodi cells, containing $3 \times 10^{4}$ viable cells, were plated in 24 multi-well plates. To measure MTT reduction by colorimetric assay, the cells were washed and incubated for $3 \mathrm{~h}$ in $100 \mu \mathrm{l}$ DMEM without phenol red (D2429, Sigma-Aldrich; Merck KGaA), and supplemented with $0.45 \mathrm{mg} / \mathrm{ml}$ MTT. The medium was then replaced by $100 \mu \mathrm{l}$ $0.1 \mathrm{M} \mathrm{HCl}$ in isopropanol and the cells were incubated at $37^{\circ} \mathrm{C}$ for $30 \mathrm{~min}$ for lysis. The insoluble formazan was resuspended and optical densities were measured at a wavelength of $570 \mathrm{~nm}$ using a microplate reader (BioTek Synergy Microplate Reader; BioTek Instruments, Inc.), according to the MTT manufacturer's protocol. The results represent the mean of 3 experiments, each performed in duplicate.

Cell growth analysis. To analyse cell growth, $2 \times 10^{4}$ cells were seeded in a 24-well culture plate, trypsinized and counted every 24 h, i.e., 24 (T24 h), 48 (T48 h), 72 (T72 h) and 96 h (T96 h) after seeding, using a Burker chamber apparatus. The experiments were carried out in triplicate for each experimental point.

Western blot analysis. Total protein extracts were isolated from the RKO cells treated with PBS or PBS-Nitrodi for 6 weeks as previously described (16). Concentrations were determined by using a protein assay kit adopting bovine serum albumin standards, according to the manufacturer's instructions (Bio-Rad Laboratories, inc.). Proteins were separated by SDS-polyacrylamide gel electrophoresis at a $12 \%$ concentration, and the blots were prepared as previously described (17). Nitrocellulose membranes were stained with a Ponceau solution $0.1 \%(\mathrm{w} / \mathrm{v})$ in $5 \%$ acetic acid (P7170, Sigma-Aldrich; Merck KGaA) for $5 \mathrm{~min}$ at room temperature. After blocking, the membranes were incubated in a solution containing the primary antibody overnight at $4^{\circ} \mathrm{C}$. Primary antibody against cyclooxygenase (COX)-2 (rabbit polyclonal anti-human; ab15191; dilution 1:1,000) was from Abcam; MMP2 antibody (rabbit polyclonal 1 anti-human; NB200-193, diluition 1:10,000) was from Novus Biologicals. The anti-GAPDH (mouse monoclonal anti-human; sc-69778; diluition 1:50,000) antibody was from Santa Cruz Biotechnology, Inc. The membranes were probed with peroxidase-conjugated secondary antibodies 
A

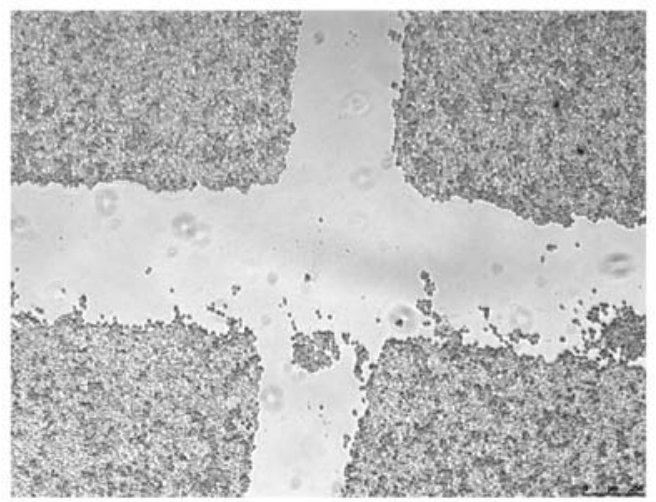

C

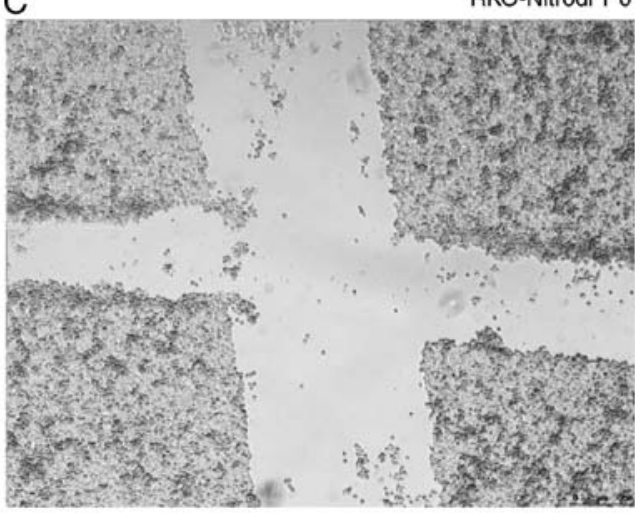

B

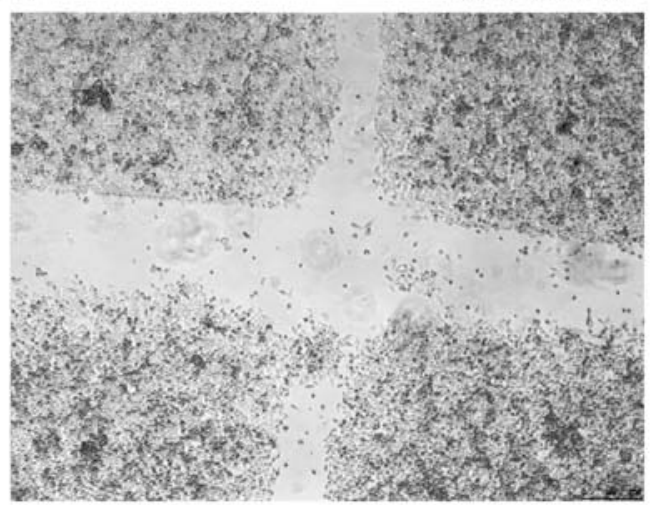

RKO-Nitrodi T24 h

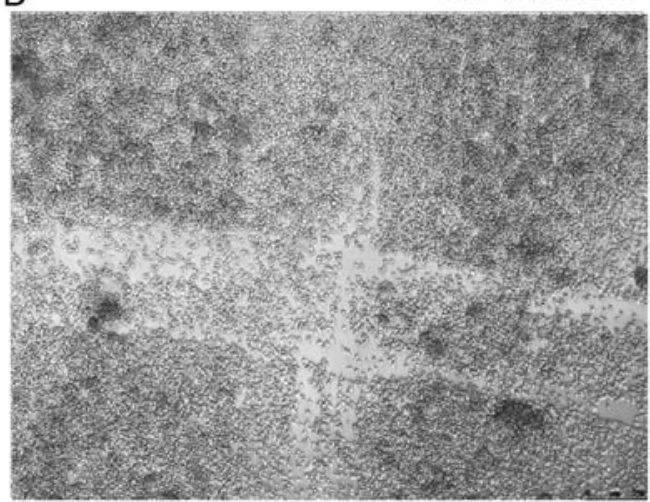

Figure 1. Nitrodi spring water promotes cell migration in an in vitro wound healing assay. Brightfield images at x5 magnification of RKO-PBS control cells and RKO-Nitrodi-treated cells, during wound healing assay. Wound closures were imaged immediately after scratching (T0), in (A) PBS-treated and (C) Nitrodi-treated cells, and 24 h later (T24 h), in (B) PBS-treated and (D) Nitrodi-treated cells.

against rabbit (rabbit monoclonal anti-human; \#7074S; Cell Signaling Technology, Inc.; dilution, 1:3,000) or mouse IgG (monoclonal anti-mouse; \#7076S; Cell Signaling Technology, Inc.; dilution, 1:3,000) for $1 \mathrm{~h}$ at room temperature and immunoreactive bands were detected using the enhanced chemiluminescence HRP Substrate Immobilon Western (EMD Millipore). The experiment was repeated 3 times. Densitometry was performed using ImageJ software $1.45 \mathrm{~s}$.

Fluorometric detection of S-nitrosothiols. The fluorometric method reported by Wink et al (18) was used to detect S-nitrosolthiols. Briefly, the RKO cells were treated with PBS or Nitrodi-PBS as described above. Following total protein extraction, $100 \mu \mathrm{g}$ proteins were reacted with $100 \mu \mathrm{M}$ 2,3-diaminonaphthalene in the presence of $100 \mu \mathrm{M}$ of $\mathrm{HgCl}_{2}$, for each sample, and incubated in the dark for $30 \mathrm{~min}$ at room temperature. The generated fluorescent compound 2,3-napththyltrazole was then measured at an excitation wavelength of $375 \mathrm{~nm}$ and an emission wavelength of $450 \mathrm{~nm}$, with a microplate reader (BioTek Synergy Microplate Reader; BioTek Instruments, Inc.).

Detection of protein $S$-nitrosocysteine post-translational modifications. Protein S-nitrosocysteine post-translational modifications were detected using the Pierce ${ }^{\mathrm{TM}} \mathrm{S}$-Nitrosylation Western Blot assay according to the manufacturer's instructions (Pierce; Thermo Fisher Scientific, Inc.). In brief, unmodified cysteines were first blocked using a sulfhydryl-reactive compound, the methyl methanethiosulfonate. S-nitrosylated cysteines were then selectively reduced with ascorbate in HENS Buffer for specific labeling with iodoTMTzero reagent, which irreversibly binds to the cysteine thiol that was S-nitrosylated. The detection of the TMT reagent-modified proteins is facilitated using an anti-TMT antibody provided by the assay.

Statistical analysis. All data were obtained from at least 3 independent experiments and are reported as the means \pm standard error of the mean (SEM). The Student's t-test was used to evaluate differences between 2 groups. $\mathrm{P}<0.05$ was considered to indicate a statistically significant difference. All experiments were repeated 3 times as biological replicates that produced the same results.

\section{Results}

Nitrodi spring water promotes cell migration and viability. To investigate the effects of Nitrodi spring water on cell migration in vitro, wound healing and Boyden chamber migration assays were performed, as described in 'Materials and methods', and it was found that Nitrodi water promoted cell migration. In fact, as shown in Fig. 1, at $24 \mathrm{~h}$ after scratching, the wounds were almost completely healed in the cells treated with PBS-Nitrodi (Fig. 1C and D), whereas the size of the wounds in the cells incubated with PBS alone remained essentially unaltered (Fig. 1A and B). Similar results were obtained in the Boyden 
A RKO-PBS
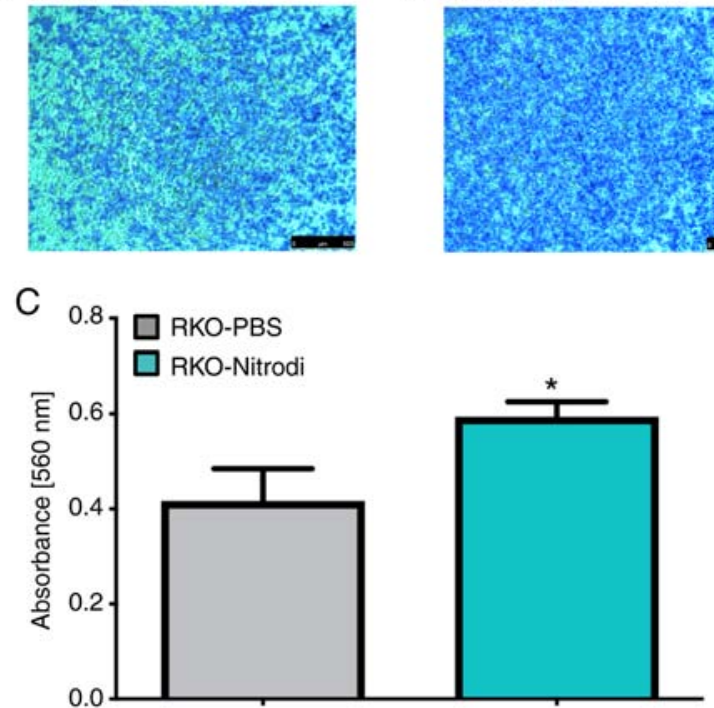

Figure 2. Nitrodi spring water promotes cell migration in in vitro Transwell migration assay. Brightfield images at $\mathrm{x} 4$ magnification of crystal violet staining of (A) RKO-PBS and (B) RKO-Nitrodi cells. (C) Crystal violet optical density of migrated cells, measured at a wavelength of $560 \mathrm{~nm}$ with a microplate reader. Bars represent the mean absorbance \pm SEM of experiments performed in triplicate. ${ }^{*} \mathrm{P}<0.05$ (statistically significant difference; t-test).

chamber assay (Fig. 2). Nitrodi water promoted the migration of the RKO cells, as shown by the crystal violet staining images of the PBS-control cells (Fig. 2A) and Nitrodi water-treated cells (Fig. 2B). Indeed, the crystal violet optical density of the migrated cells, measured at a wavelength of $540 \mathrm{~nm}$, was 0.416 and $0.594 \mathrm{~nm}$ in the PBS and PBS-Nitrodi-treated cells, respectively (Fig. 2C). Moreover, as shown in Fig. 3A and $\mathrm{B}$, cell viability was approximately $62 \%$ greater in the cells treated with Nitrodi water than in those treated with PBS alone. The mean optical density values, measured at a wavelength of $570 \mathrm{~nm}$, were 0.0474 and $0.0758 \mathrm{~nm}$ in the PBS and PBS-Nitrodi-treated cells, respectively (Fig. 3B). Furthermore, the Nitrodi-treated cells grew at a significantly faster rate than the PBS-control cells (Fig. 4).

Nitrodi spring water exerts anti-inflammatory effects in vitro. To investigate whether COX-2 enzyme regulation is involved in the therapeutic effects exerted by Nitrodi spring water on inflammatory diseases (11), the expression of the COX-2 enzyme and that of its direct target, metalloprotease-2 (MMP2), were examined in the present study. To this aim, a western blot analysis of the total protein extract from RKO-PBS or RKO-Nitrodi cells was performed. As shown in Fig. 5A, following immunostaining and autoradiography, the COX-2 antibody recognized two signals of approximately 70 and $72 \mathrm{kDa}$, respectively. It was considered that these 2 signals correspond to a light form (COX-L) and to the S-nitrosylated active form (COX-H). As shown in Fig. 5A and B, COX-H expression was higher in the RKO-PBS cells than in the RKO-Nitrodi cells, whereas the expression of the COX-L isoform was significantly higher in the RKO-Nitrodi cells. To verify the hypothesis that Nitrodi water induces COX-2 inactivation, an immunostaining assay against MMP2 was

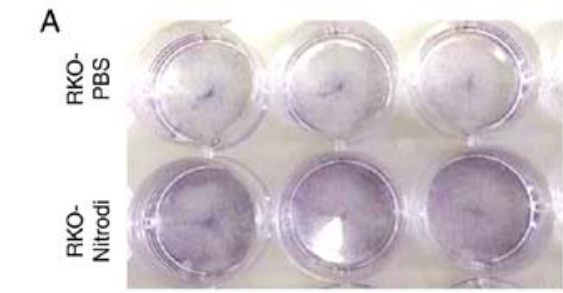

B

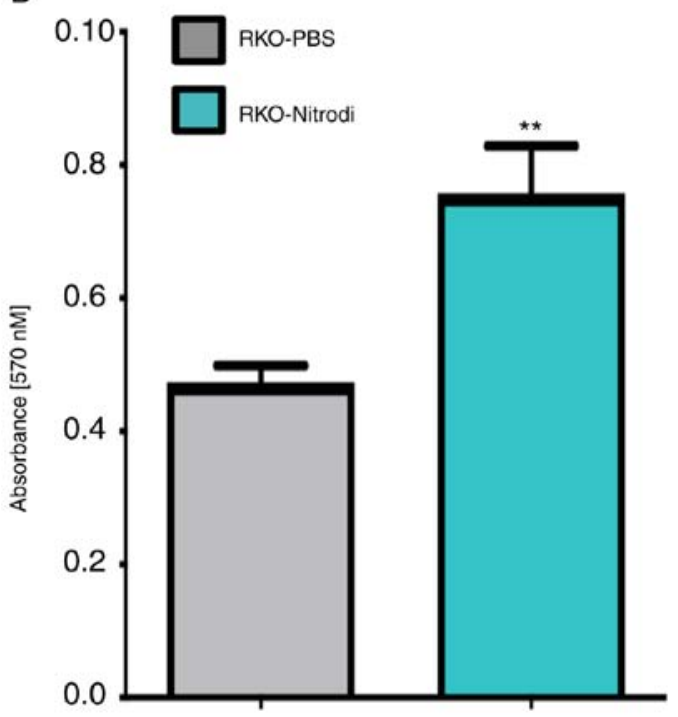

Figure 3. Nitrodi spring water promotes in vitro cell viability. (A) Images of water-insoluble formazan produced by MTT assay. (B) Analysis of resuspended salts measured at a wavelength of $570 \mathrm{~nm}$ by a microplate reader. Bars represent the mean absorbance \pm SEM of experiments performed in triplicate. ${ }^{* *} \mathrm{P}<0.005$ (statistically significant difference; t-test).

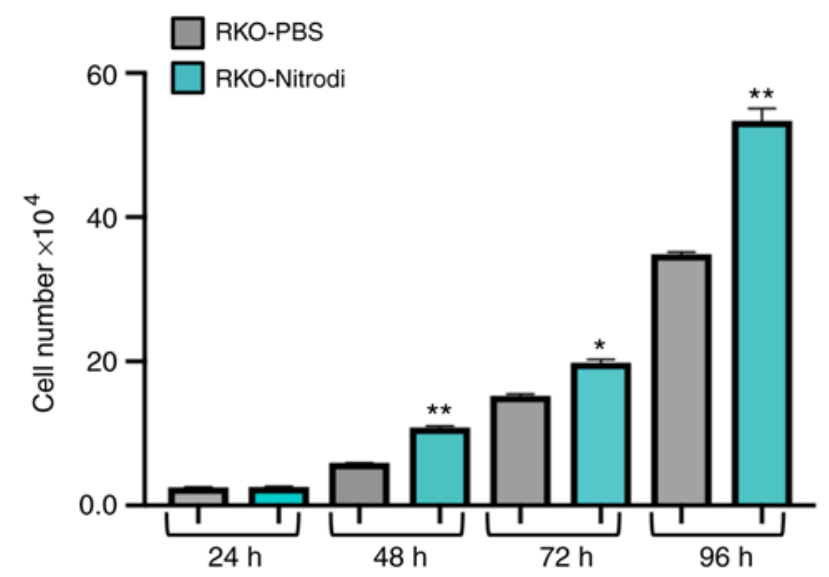

Figure 4. Nitrodi spring water promotes in vitro cell growth. Bars represent the mean cell number counted of RKO-PBS and RKO-Nitrodi cells \pm SEM, at the experimental time of T24, T48, T72 and T96 h, as described in 'Materials and methods' section. ${ }^{*} \mathrm{P}<0.05$ and ${ }^{* *} \mathrm{P}<0.005$ (statistically significant difference; t-test).

performed, which is a COX-2 downstream target. As shown in Fig. 5, MMP2 protein expression was markedly downregulated in the RKO-Nitrodi cells compared with the RKO-PBS control cells.

Nitrodi spring water downregulates protein S-nitrosylation. To investigate whether Nitrodi water downregulates protein 


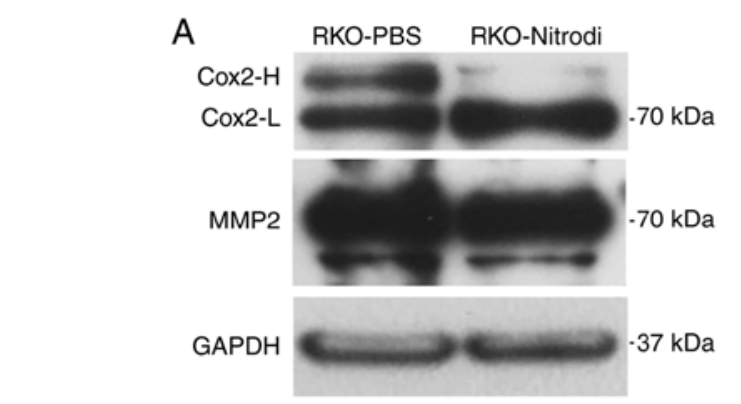

B

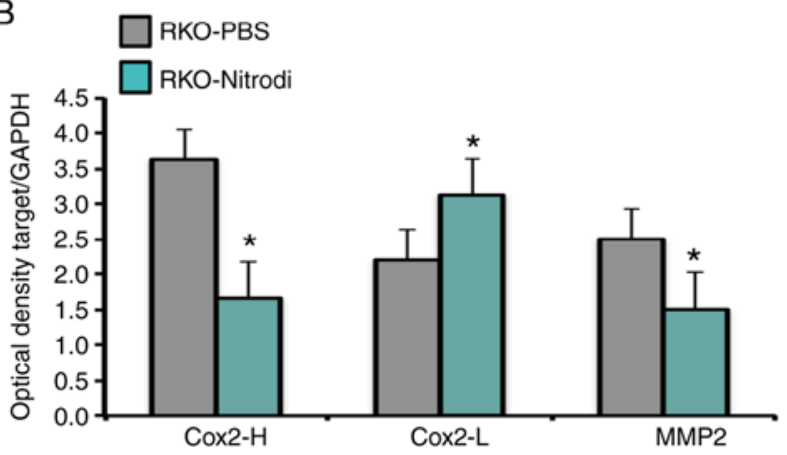

Figure 5. Nitrodi spring water induces changes in COX-2 and MMP2 expression. (A) Representative western blot images showing the expression of COX-2, and MMP2 protein levels in PBS- and Nitrodi water-treated cells. GAPDH was used as a loading control. (B) The graph shows the densitometric analysis of COX-2-H isoform, COX-2-L isoform and MMP2, compared to GAPDH. Bar graphs represent means \pm SEM (3 independent experiments). ${ }^{*} \mathrm{P}<0.05$ (statistically significant difference vs. RKO-PBS cells; t-test).

S-nitrosylation, the fluorometric detection of S-nitrosothiol and S-nitrosylation western blot analysis were performed. The specific reaction between 2,3-diaminonaphthalene and $\mathrm{HgCl}_{2}$, performed to detect S-nitrosothiols, generates the fluorescent compound 2,3-napththyltrazole that emits light at a wavelength of $450 \mathrm{~nm}$. As shown in Fig. 6A, the measured emitted light at a wavelength of $450 \mathrm{~nm}$, was approximately $50 \%$ lower in the RKO-Nitrodi cells than in the RKO-PBS control cells. The mean OD values were 176 in the RKO-PBS and 93 and in the RKO-Nitrodi cells. These results were confirmed by an S-nitrosylation western blot analysis that revealed the marked downregulation of protein S-nitrosylation in the RKO-Nitrodi cells (Fig. 6B). Ponceau staining and GAPDH protein served as internal controls (Fig. 6C).

\section{Discussion}

Balneotherapy and the assumption of thermal mineral water have long been used in the treatment of diseases such as atopic dermatitis, psoriasis, rheumatoid arthritis and osteoarthritis, as well as metabolic and psychological diseases. This treatment, alone or in combination with orthodox medical treatments, has exhibited a renaissance over the past decade (19). Balneotherapy exerts three types of effects: mechanical or hydrostatic effects, thermal effects depending on the temperature of the water, and chemical effects depending the composition of the water that can be salty, sulfurous, bicarbonated, carbonic, and/or enriched in other specific elements. A limit of balneotherapy is that the mechanisms through which each element contributes to the therapeutic effects are unknown. Moreover, the
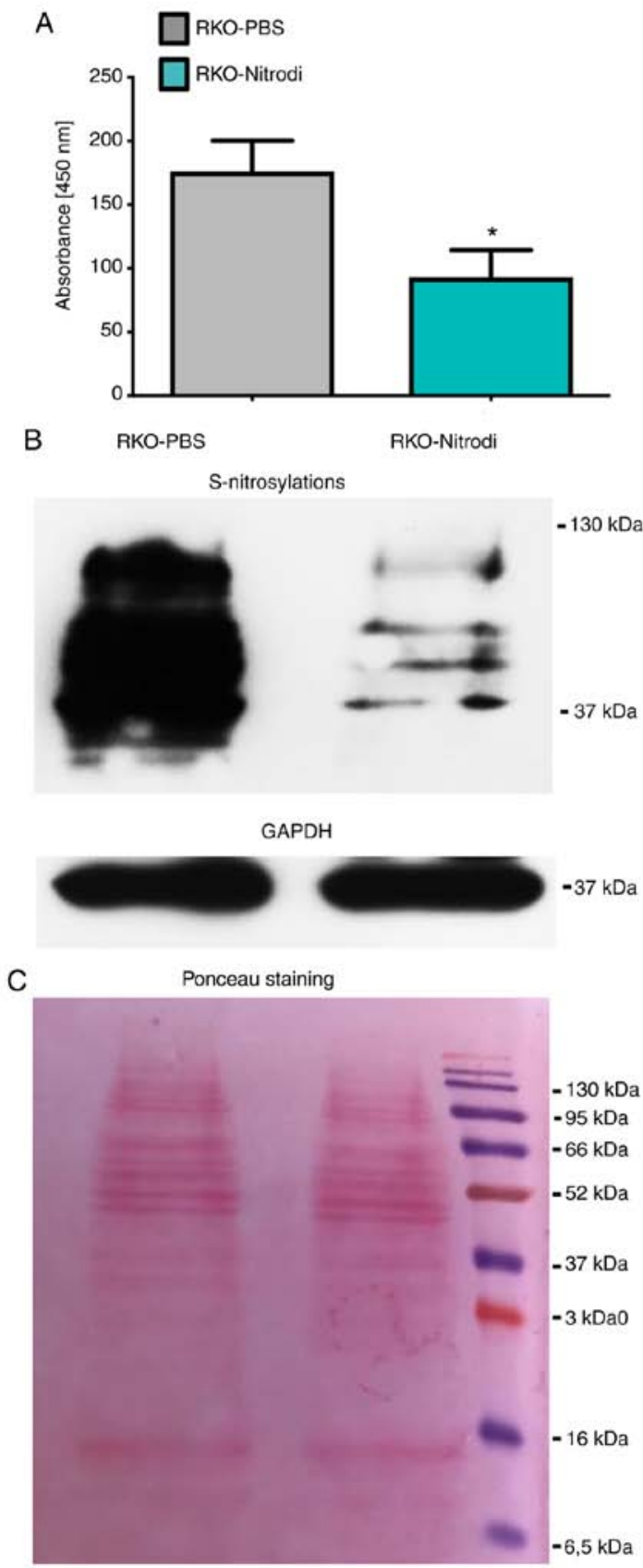

Figure 6. Nitrodi spring water induces the downregulation of protein S-nytrosilation. Protein S-nitrosocysteine post-translational modifications were detected by using the Pierce ${ }^{\mathrm{TM}} \mathrm{S}$-nitrosylation western blot assay, as described in 'Materials and methods' section. (A) Fluorometric detection of S-nitrosothiols was measured at a wavelength of $450 \mathrm{~nm}$ by a microplate reader. Bars represent the mean absorbance \pm SEM of experiments performed in triplicate ${ }^{*} \mathrm{P}<0.05$ (statistically significant difference; t-test). (B) Representative western blot image of S-nitrosylated proteins (TMT reagent-modified proteins detected with anti-TMT antibody). GAPDH was used as a loading control. (C) Representative Ponceau staining image following SDS-Page electrophoresis of proteins extracted from RKO-PBS and RKO-Nitrodi cells.

biological mechanisms through which mineral-medicinal water alleviates the symptoms of diseases remain largely obscure. However, it has been well documented that balneotherapy exerts anti-inflammatory, analgesic and antioxidant effects together with neuroendocrine-immune regulation in various disorders $(2,20-22)$. 
The aim of the present study was to shed light on the molecular mechanisms sustaining the therapeutic efficacy of Nitrodi spring water and to provide a robust scientific basis that can improve its application in balnelogical therapy and hydroponic therapy. To this aim, RKO cells were treated with PBS-Nitrodi water or PBS alone as control, for $4 \mathrm{~h} /$ day, 5 days/week, for a total of 6 weeks. This in vitro protocol mimics the in vivo treatment offered to patients and analyses the effects of Nitrodi water on cell features and metabolism. Using this strategy, it was demonstrated that Nitrodi spring water promotes the motility and viability of RKO cells and induces the downregulation of protein S-nitrosylation.

$\mathrm{S}$-nitrosylation is an important post-translational modification induced by nitric oxide (NO), and consists in the coupling of the NO molecule to a reactive cysteine thiol to form an S-nitrosothiol (23-28). S-Nitrosylation is implicated in the regulation of carbohydrate and lipid metabolism, and, moreover, aberrant S-nitrosylation of proteins is associated to cardiovascular, pulmonary, musculoskeletal diseases, to neurological dysfunction and to cancer (29-33). Accumulating evidence suggests that NO production and S-nitrosylation dysregulation are key events in the beginning of neurodegeneration (34) and neuronal dysfunction in Alzheimer's disease (35). NO is also a key messenger in the pathogenesis of inflammation and exerts this effect by activating innate and adaptive immunity (36).

The S-nitrosylation of COX-2 negatively regulates its enzymatic activity $(37,38)$. In the present study, following immunostaining and autoradiography, the COX-2 antibody recognized a light form of approximately $70 \mathrm{kDa}(\mathrm{COX}-\mathrm{L})$ and another isoform of approximately $72 \mathrm{kDa}$ attributable to the S-nitrosylated active form (COX-H). The difference in mass may be compatible with a different nitrosylation level of COX-2 cysteine residues; however, molecular mass measured by western blot analysis is not very precise. In accordance with this finding and with the therapeutic effects of Nitrodi water, higher levels of un-nitrosylated total proteins were found in cells treated with PBS-Nitrodi water than in PBS-treated control cells. Notably, these findings suggest that the levels of the un-nitrosylated isoform of the COX-2 enzyme were higher in the RKO-Nitrodi cells than in the RKO-PBS cells. In accordance with this hypothesis, the downstream COX-2 target MMP2 was also downregulated following exposure to Nitrodi water.

The COX-2 enzyme plays a key role in the arachidonic acid conversion to eicosanoids, thereby promoting inflammation and tumour progression. The present study suggested that the molecular mechanisms through which Nitrodi spring water exerts its anti-inflammatory effects may involve COX-2 inactivation through the downregulation of protein S-Nitrosylation. Given the crucial role that both the S-nitrosylation of proteins and the inflammatory cascade play in cell signalling, cell function and diseases pathogenesis (23-33), the findings of the present study support the application of Nitrodi spring water in the treatment of diseases, such as osteoarthritis. Notably, it has recently been demonstrated that osteoarthritis is caused by the inflammatory response to high fluid shear stress (39). High fluid shear stress induces COX-2 activation that, in turn, activates the expression of prostaglandins, MMPs and pro-inflammatory cytokines (40). Furthermore, patients affected by rheumatoid arthritis, psoriatic arthritis, reactive arthritis or osteoarthritis also have high levels of PGF2 $\alpha$ (41). These observations are in agreement with the well-known beneficial therapeutic effects of Nitrodi water on inflammatory diseases, such as osteoarthritis $(2,3)$.

The data of the present study coincide with the finding that mineral waters exert a positive therapeutic effect on the antioxidant system, particularly sulphurous mineral water $(42,43)$. It has also been demonstrated that hydrogen sulphide, released from sulphur, increased the release of anti-inflammatory cytokines (44). It is conceivable that a similar mechanism of action could also be responsible for the anti-inflammatory properties of Nitrodi spring water, and that other mineral spring waters could act in a similar manner or by modifying other general molecular and biochemical cell mechanisms, such as microRNA expression (45).

However, cell biology studies on the molecular basis of the properties of thermal waters worldwide are limited. To our knowledge, Italy represents a unique case in that it is particularly rich in springs that share the same therapeutic effects and that have similar salt and thermal features to the Nitrodi spring water, probably since they have the same hydro-geological origin. For example, the Lepoldine water of Montecatini Terme in Tuscany exerts anti-inflammatory effects (46), and is also effective in the treatment of atopic dermatitis, seborrhoea and psoriasis (47). Research on the possible therapeutic effects of other hot springs with comparable salt content and thermal features worldwide should be encouraged.

Although Nitrodi water promoted the mobility and proliferation of the colon cancer RKO cell line, it also induced the downregulation of MMP2 expression, probably via COX2 inactivation, both molecules involved in cancer progression, metastases and inflammation $(48,49)$. It has recently been demonstrated that MMP inhibitor is able to suppress the metastatic progression of cancer (50). Furthermore, Nitrodi water downregulates protein S-nitrosylation which modulates cell signalling towards inflammation (51). It was hypothesized that these effects, which could act synergistically, are the molecular basis of the beneficial effects that Nitrodi water could exert on several diseases (11).

The present study provides preliminary results that should be verified in in vitro studies performed on non-cancerous cell lines and in vivo. Additional experiments are required to confirm the role of Nitrodi water on COX-2 S-nitrosylation, using the S-nitrosylation biotin switch assay to precipitate nitrosylated protein and specific COX-2 detection by western blot analysis (52). Taking into consideration the association between NO and S-nitrosylation (53), inducible nitric oxide synthase inhibitors, such as N-nitro-L-arginine-methyl ester (L-NAME), need to be used in the future to perform a negative experimental control. Furthermore, future perspectives in thermal water research may also aim to evaluate, in greater depth, the protective effects that Nitrodi water exerts against inflammatory stimulation, such as I1-6, in non-cancerous cells and to explore the cytokine expression pattern following in vitro incubation in Nitrodi water.

\section{Acknowledgements}

The authors would like to thank Jean Ann Gilder (Scientific Communication srl, Naples, Italy) for editing the text. The 
authors would also like to Giuseppe Di Meglio (Fonti delle NinfeNitrodi, via pendio Nitrodi, 80070 Barano d'Ischia; termedinitrodi@gmail.com) for supplying the Nitrodi water.

\section{Funding}

The present study was funded by a grant from FORST-Fondazione per la Ricerca Termale-2018.

\section{Availability of data and materials}

All data generated or analysed during this study are included in this published article. No datasets were generated or analysed during the current study.

\section{Authors' contributions}

PI, ADP, MDR and FWR participated in the conception and design of the study. FC and AA performed the cellular and molecular experiments. MDR performed the statistical analysis of the data. PI and ADP coordinated the work. MDR and FWR contributed to data interpretation and wrote the manuscript. PI and ADP critically revised the manuscript. PI provided funding. All authors edited and approved the final version of the manuscript.

\section{Ethics approval and consent to participate}

Not applicable.

\section{Patient consent for publication}

Not applicable.

\section{Competing interests}

The authors declare that they have no competing interests.

\section{References}

1. Matsumoto S: Evaluation of the role of balneotherapy in rehabilitation medicine. J Nippon Med Sch 85: 196-203, 2018.

2. Gálvez I, Torres-Piles S and Ortega-Rincón E: Balneotherapy, immune system, and stress response: A hormetic strategy? Int J Mol Sci 19: 1687, 2018.

3. Huang A, Seite S and Adar T: The use of balneotherapy in dermatology. Clin Dermatol 36: 363-368, 2018.

4. Andreassi L and Flori L: Mineral water and spas in Italy. Clin Dermatol 14: 627-632, 1996.

5. Ricciardi E, Ricciardi CA and Ricciardi B: Treatment of kidney diseases in the thermal springs of Pithecusa during the XVIII Century. G Ital Nefrol 33 (Suppl 66): 33.S66.26, 2016.

6. Forti L: Rilievi dedicati alle ninfe nitrodi. In: Rendiconti dell'Accademia di Archeologia. Lettere e Belle Arti-Napoli, New Series 26, pp161-191, 1951.

7. Nasermoaddeli A and Kagamimori S: Balneotherapy in medicine: A review. Environ Health Prev Med 10: 171-179, 2005.

8. Petraccia L, Liberati G, Masciullo SG, Grassi M and Fraioli A Water, mineral waters and health. Clin Nutr 25: 377-85, 2006.

9. Marotta and Sica: Classificazione italiana delle acque minerali. Annuali di Chimica Applicata 19: 1929.

10. Marotta and Sica: Classificazione italiana delle acque minerali. Annuali di Chimica Applicata 23: 1933.
11. Mancioli M: Le proprietà terapeutiche delle acque Nitrodi e Olmitello. Li Causi Editore, Bologna, 1984

12. Yuan H, Liddle FJ, Mahajan S and Frank DA: IL-6-induced survival of colorectal carcinoma cells is inhibited by butyrate through down-regulation of the IL-6 receptor. Carcinogenesis 25 : 2247-2255, 2004

13. Unver N and McAllister F: IL-6 family cytokines: Key inflammatory mediators as biomarkers and potential therapeutic targets. Cytokine Growth Factor Rev 41: 10-17, 2018.

14. Turano M, Costabile V, Cerasuolo A, Duraturo F, Liccardo R, Delrio P, Pace U, Rega D, Dodaro CA, Milone M, et al: Characterisation of mesenchymal colon tumour-derived cells in tumourspheres as a model for colorectal cancer progression. Int J Oncol 53: 2379-2396, 2018.

15. Cammarota F, Conte A, Aversano A, Muto P, Ametrano G, Riccio P, Turano M, Valente V, Delrio P, Izzo P, et al: Lithium chloride increases sensitivity to photon irradiation treatment in primary mesenchymal colon cancer cells. Mol Med Rep 21: 1501-1508, 2020.

16. Galatola M, Paparo L, Duraturo F, Turano M, Rossi GB, Izzo P and De Rosa M: Beta catenin and cytokine pathway dysregulation in patients with manifestations of the 'PTEN hamartoma tumor syndrome'. BMC Med Genet 13: 28, 2012.

17. Costabile V, Duraturo F, Delrio P, Rega D, Pace U, Liccardo R, Rossi GB, Genesio R, Nitsch L, Izzo P and De Rosa M: Lithium chloride induces mesenchymal to epithelial reverting transition in primary colon cancer cell cultures. Int J Oncol 46: 1913-1923, 2015.

18. Wink DA, Kim S, Coffin D, Cook JC, Vodovotz Y, Chistodoulou D, Jourd'heuil D and Grisham MB: Detection of S-nitrosothiols by fluorometric and colorimetric methods. In Methods Enzymol 301: 201-211, 1999.

19. Nasermoaddeli A and Kagamimori S: Balneotherapy in medicine: A review. Environ Health Prev Med 10: 171-179, 2005.

20. Ortega E, Gálvez I, Hinchado MD, Guerrero J, Martín-Cordero L and Torres-Piles S: Anti-inflammatory effect as a mechanism of effectiveness underlying the clinical benefits of pelotherapy in osteoarthritis patients: Regulation of the altered inflammatory and stress feedback response. Int J Biometeorol 61: 1777-1785, 2017.

21. Galvez I, Torres-Piles S, D Hinchado M, Alvarez-Barrientos A, Torralbo-Jimenez P, Guerrero J, Martin-Cordero L and Ortega E: Immune-neuroendocrine dysregulation in patients with osteoarthritis: A revision and a pilot study. Endocr Metab Immune Disord Drug Targets 17: 78-85, 2017

22. Matz H, Orion E and Wolf R: Balneotherapy in dermatology. Dermatol Ther 16: 132-140, 2003.

23. Ehrenfeld P, Cordova F, Duran WN and Sanchez FA: $\mathrm{S}$-nitrosylation and its role in breast cancer angiogenesis and metastasis. Nitric Oxide 87: 52-59, 2019.

24. Iwakiri Y, Satoh A, Chatterjee S, Toomre DK, Chalouni CM, Fulton D, Groszmann RJ and Sessa WC: Nitric oxide synthase generates nitric oxide locally to regulate compartmentalized protein S-nitrosylation and protein trafficking. Proc Natl Acad Sci USA 103: 19777-19782, 2006.

25. Marín N, Zamorano P, Carrasco R, Mujica P, González FG, Quezada C, Meininger CJ, Boric MP, Durán WN and Sánchez FA: S-Nitrosation of $\beta$-catenin and p120 catenin: A novel regulatory mechanism in endothelial hyperpermeability. Circ Res 111: 553-563, 2012.

26. Guequén A, Carrasco R, Zamorano P, Rebolledo L, Burboa P, Sarmiento J, Boric MP, Korayem A, Durán WN and Sánchez FA: S-nitrosylation regulates VE-cadherin phosphorylation and internalization in microvascular permeability. Am J Physiol Heart Circ Physiol 310: H1039-H1044, 2016.

27. Stamler JS, Simon DI, Jaraki O, Osborne JA, Francis S, Mullins M, Singel D and Loscalzo J: S-nitrosylation of tissue-type plasminogen activator confers vasodilatory and antiplatelet properties on the enzyme. Proc Natl Acad Sci USA 89: 8087-8091, 1992.

28. Rizi BS, Achreja A and Nagrath D: Nitric oxide: The forgotten child of tumor metabolism. Trends in cancer 3: 659-672, 2017.

29. Foster MW, Hess DT and Stamler JS: Protein S-nitrosylation in health and disease: A current perspective. Trends Mol Med 15: 391-404, 2009.

30. Nakamura T and Lipton SA: 'SNO'-storms compromise protein activity and mitochondrial metabolism in neurodegenerative disorders. Trends Endocrinol Metab 28: 879-892, 2017.

31. Narne P, Pandey V and Phanithi PB: Role of nitric oxide and hydrogen sulfide in ischemic stroke and the emergent epigenetic underpinnings. Mol Neurobiol 56: 1749-1769, 2019. 
32. Plenchette S: Role of S-nitrosylation in the extrinsic apoptotic signalling pathway in cancer. Redox Biol 5: 415, 2015.

33. Wei W, Li B, Hanes MA, Kakar S, Chen X and Liu L: S-nitrosylation from GSNOR deficiency impairs DNA repair and promotes hepatocarcinogenesis. Sci Transl Med 2: 19ra13, 2010.

34. Liu C, Liang MC and Soong TW: Nitric oxide, iron and neurodegeneration. Front Neurosci 13: 114, 2019.

35. Spiers JG, Chen HJC, Bourgognon JM and Steinert JR: Dysregulation of stress systems and nitric oxide signaling underlies neuronal dysfunction in Alzheimer's disease. Free Radic Biol Med 134: 468-483, 2019.

36. García-Ortiz A and Serrador JM: Nitric oxide signaling in T cell-mediated immunity. Trends Mol Med 24: 412-427, 2018

37. Kim SF, Huri DA and Snyder SH: Inducible nitric oxide synthase binds, S-nitrosylates, and activates cyclooxygenase- 2 . Science 310: 1966-1970, 2005.

38. Alexanian A and Sorokin A: Cyclooxygenase 2: Protein-protein interactions and posttranslational modifications. Physiol Genomics 49: 667-681, 2017.

39. Guan PP, Ding WY and Wang P: The roles of prostaglandin F2 in regulating the expression of matrix metalloproteinase-12 via an insulin growth factor-2-dependent mechanism in sheared chondrocytes. Signal Transduct Target Ther 3: 27, 2018.

40. Goldring MB: Osteoarthritis and cartilage: The role of cytokines. Curr Rheumatol Rep 2: 459-465, 2000.

41. Basu S, Whiteman M, Mattey D and Halliwell B: Raised levels of $\mathrm{F}(2)$-isoprostanes and prostaglandin $\mathrm{F}(2 \mathrm{alpha})$ in different rheumatic diseases. Ann Rheum Dis 60: 627-631, 2001.

42. Fioravanti A, Karagülle $M$, Bender T and Karagülle MZ: Balneotherapy in osteoarthritis: Facts, fiction and gaps in knowledge. Eur J Integr Med 9: 148-150, 2017.

43. Jantz MA and Antony VB: Pathophysiology of the Pleura Respiration 75: 121-133, 2008

44. Prandelli C, Parola C, Buizza L, Delbarba A, Marziano M, Salvi V,Zacchi V, Memo M, Sozzani S, Calza S, et al: Sulphurous thermal water increases the release of the anti-inflammatory cytokine IL-10 and modulates antioxidant enzyme activity. Int J Immunopathol Pharmacol 26: 633-646, 2013.
45. Karagülle MZ, Karagülle M, Kılıç S, Sevinc H, Dündar C and Türkoğlu M: In vitro evaluation of natural thermal mineral waters in human keratinocyte cells: A preliminary study. Int J Biometeorol 62: 1657-1661, 2018.

46. Tsoureli-Nikita E, Menchini G, Ghersetich I and Hercogova J: Alternative treatment of psoriasis with balneotherapy using leopoldine spa water. J Eur Acad Dermatol Venereol 16: 260-262, 2002.

47. Augustin M, Alvaro-Gracia JM, Bagot M, Hillmann O, van de Kerkhof PCM, Kobelt G, Maccarone M, Naldi L and Schellekens H: A framework for improving the quality of care for people with psoriasis. J Eur Acad Dermatol Venereol 26 (Suppl 4): S1-S16, 2012.

48. De Jager SCA and Hoefer IE: Beyond the matrix: MMP2 as critical regulator of inflammation-mediated vascular dysfunction. Cardiovasc Res 113: 1705-1707, 2017.

49. Fingleton B: Matrix metalloproteinases as regulators of inflammatory processes. Biochim Biophys Acta Mol Cell Res 1864: 2036-2042, 2017.

50. Lyu Y, Xiao Q, Yin L, Yang L, Wei H and He W: Potent delivery of an MMP inhibitor to the tumor microenvironment with thermosensitive liposomes for the suppression of metastasis and angiogenesis. Signal Transduct Target Ther 4: 26, 2019.

51. Dasgupta S, Gomez JJ, Singh I and Khan M: S-Nitrosylation in regulation of inflammation and cell damage. Curr Drug Targets 19: 1831-1838, 2018.

52. Forrester MT, Foster MW, Benhar M and Stamler JS: Detection of protein S-nitrosylation with the biotin-switch technique. Free Radical Bio Med 46: 119-126, 2009.

53. Martínez-Ruiz A, Cadenasa S and Lamas S: Nitric oxide signaling: Classical, less classical, and nonclassical mechanisms. Free Radical Bio Med 51: 17-29, 2011.

This work is licensed under a Creative Commons Attribution-NonCommercial-NoDerivatives 4.0 International (CC BY-NC-ND 4.0) License. 